\title{
Pendampingan Manajemen Usaha Bersama Simpan Pinjam (UBSP) Komunitas Aditya Yodha Di Dusun Sorowangsan Girikerto Turi Sleman DIY
}

\author{
Penulis $^{1}$ \\ Insiwijati Prasetyaningsih \\ Program Studi Manajemen, Fakultas Bisnis Universitas Kristen Duta Wacana \\ J1. Dr Wahidin Sudirohusodo no 5 - 21 Yogyakarta \\ Email : insiwijati@staff.ukdw.ac.id \\ Penulis $^{2}$ \\ Suprianus Nahak \\ Mahasiswa Program Studi Manajemen, Fakultas Bisnis, Universitas Kristen Duta Wacana \\ Jl. Dr Wahidin Sudirohusodo no 5 - 21 Yogyakarta \\ Email : ipylateck@gmail.com
}

Abstrak - Komunitas Aditya Yodha melakukan Kerjasama dengan Pembinaan Kesejahteraan Keluarga (PKK) mengembangkan berbagai usaha misalnya olahan salak, ternak kambing, ikan nila yang merupakan hasil pertanian khas dusun Sorowangsan Turi, untuk meningkatkan kesejahteraan.. Dalam masa pandemic covid 19 seperti saat ini memerlukan pemikiran lebih kreatif untuk mandiri. Dalam rangka mengembangkan usaha tersebut dibutuhkan permodalan. Sumber dana permodalan yang dapat mendukung usaha antara lain Usaha Bersama Simpan Pinjam (UBSP) agar usaha kelompok berkembang berkelanjutan, maka kemudian komunitas membentuk UBSP. Untuk itu akan dilakukan pendampingan dan pelatihan. Pendampingan yang dilakukan dengan metode pemberdayaan yaitu proses di mana masyarakat berinisiatif untuk memulai kegiatan untuk memperbaiki situasi dan kondisi diri sendiri. Pelatihan yang dilakukan adalah manajemen umum UBSP dan organisasi, manajemen keuangan, analisis usaha. Kegiatan dimulai dengan pembuatan konsep UBSP yang akan disosialisasikan kepada komunitas sesuai kondisi potensi dan SDM kelompok. Berdasarkan pemahaman UBSP, komunitas membentuk pengurus UBSP. Selanjutnya dilakukan Pelatihan dan pendampingan manajemen umum dan organisasi, manajemen keuangan, analisis usaha. Melalui UBSP dapat dilakukan modal bergulir untuk pengembangan usaha berkelanjutan. Berdasarkan uraian tersebut, luaran pengabdian masayarakat adalah konsep UBSP, materi manajemen \& organisasi, manajemen keuangan, analisis usaha, laporan pengabdian masyarakat dan artikel prosiding serta terbentuknya UBSP Aditya Yodha (AYO)

Kata Kunci : kata kunci Analisis usaha, Konsep UBSP, Manajemen keuangan, Manajemen \& organisasi,
Abstract - Aditya Yodha Community has collaborated with the local Family Welfare Empowerment (FWE) to develop various businesses, such as processed Salak (Snakesfruit), goat farm, and tilapia fish farm as the local wisdoms of Sorowangsan village to improve the welfare of the community. In the current COVID- 19 pandemic, it requires the creative thinking to be independent. To develop the business, the 
community needs capital. The sources of funds that can support the business is in the form of Joint Savings and Loans Business (JSLB) so that the group's business can develop sustainably. The community then formed JSLB. Therefore, mentoring and training would be carried out. The assistance was carried out using the empowerment method, which is a development process in which the community takes the initiative to start the social activities to improve their own situation and condition. The trainings were general management of JSLB and organization, financial management, business analysis. The activity was started with making the JSLB concept which would be socialized to groups in the community according to the group's potential and human resource conditions. Based on the JSLB concept, the community formed the JSLB management. Furthermore, the training and assistance for the general management and organization, the financial management, and the business analysis were carried out. Through $J S L B$, revolving capital can be made for sustainable business development. The outputs of this community service were the JSLB concept, the management \& organization materials, the financial management, the business analysis, the community service reports, the proceedings for journal articles and Aditya Yodha (AYO) JSLB has also been formed.

Keywords: business analysis, financial management, $J S L B$ concept, management \& organization

\section{Pendahuluan}

Masyarakat dusun Sorowangsan Girikerto Sleman merupakan masyarakat yang aktif beberapa kali memenangkan kebersihan lingkungan, mayoritas beragama muslim dan memiliki kebanggaan terhadap budaya yang selama ini dikembangkan yaitu budaya karawitaan, untuk orang tua atau orang dewasa dan anak - anak, bahkan ada wayang toyo yang merupakan budaya kuno tetap dilestarikan di daerah tersebut. Di Dusun Sorowangsan tersebut juga terdapat sanggar yang mengembangkan kreatifitas dan melestarikan budaya. Sanggar tersebut namanya komunitas Aditya Yodha yang melakukan kegiatan pendidikan untuk anak - anak mulai dari latihan tari untuk anak - anak, pendampingan belajar untuk anak anak serta mengembangkan Paud.

Tim pengabdian masyarakat ini telah mendampingi kelompok olahan salak sebagai produk pertanian khas dusun sorowangsan selama 3 tahun. Pada tahun pertama dilakukan identifikasi atau survey usaha yang akan dikembangkan dan kemudian diputuskan usaha yang akan dikembangkan adalah salak olahan, sebagai salah satu solusi salak yang menumpuk dan membusuk. Berdasarkan keputusan usaha olahan salak tersebut dilakukan pelatihan alternative produk berbagai olahan salak, Selanjutnya sebelum pandemic kelompok mencoba membuat produknya dan dijual di beberapa toko, akan tetapi ternyata ada kekurangan dari produk tersebut yaitu P-IRT, selanjutnya dilakukan proses P-IRT (1)

Selain budidaya salak, masyarakat dusun Sorowangsan juga beternak kambing. Saat ini salak lebih menguntungkan dijual sebagai buah segar. Selain olahan salah dan kambing juga dilakukan pengembangan ikan nila, sesuai daerahnya merupakan daerah gunung merapi yang memiliki air yang berlimpah. Kondisi pandemic seperti saat ini, budidaya dapat dilakukan, akan tetapi masyarakat memiliki keterbatasan modal, sehingga membutuhkan bantuan modal yang dapat digulirkan. Selama ini di dusun Sorowangsan telah dilakukan simpan pinjam akan tetapi belum produktif mendukung suatu usaha. Usaha Bersama Simpan Pinjam (UBSP) (2) merupakan sarana yang dianggap cocok untuk digunakan sebagai sarana dana bergulir yang akan dikembangkan mulai dari usaha ternak kambing bergulir Untuk itu akan dilakukan peningkatan kapasitas untuk pengembangan UBSP berupa pelatihan manajemen, manajemen keuangan UBSP dan analisis usaha atas pengembangan usaha melalui dana bergulir, melalui pembentukan UBSP.

\section{MASALAH}

1. Kelompok telah memiliki kegiatan simpan pinjam akan tetapi belum berfungsi produktif mendukung kegiatan usaha, oleh karena itu dikembangkan Usaha Bersama Simpan Pinjam (UBSP) untuk mendukung pengembangan Usaha masyarakat.

2. Keterbatasn kemampuan sehingga memerlukan pelatihan manajemen dan organisasi UBSP, manajemen keuangan, analisis usaha dan manajemen keuangan.

\section{Metode dan Pelaksanaan}

Metode yang digunakan dalam pengabdian masyarakat ini adalah dengan cara pendampingan dan pemberdayaan (3). Usaha Bersama Simpan Pinjam merupakan system pengembangan dan pemberdayaan masyarakat untuk mandiri. Masyarakat membuat kelompok UBSP untuk melakukan iuran, tabungan atau simpanan dan pinjaman untuk pengembangan usaha dan fasilitas, sehingga dapat menuju masyarakat yang mandiri dan sejahtera. Berdasarkan hal tersebut komunitas Aditya Yodha 
membentuk UBSP yang lebih berfungsi untuk melakukan pemberdayaan dan pendampingan. UBSP yang dikembangkan merupakan konsep untuk membangun masyarakat. UBSP mendukung munculnya wirausaha wirausaha yaitu personal atau pribadi yang memiliki potensi usaha dan mampu memanfaatkan potensi lingkungan. Ciputra melihat peluang di lapangan dari keadaan lingkungan dapat menjadi peluang (4). Pemberdayaan untuk mendukung kewirausahaan dapat berhasil jika mengikuti Langkah sebagai berikut (5):

a. Tekat dan kompetensi. Dimulai dari pelakunya sendiri yaitu masyarakat. Masyarakat dampingan perlu memiliki tekat yang kuat, tulus untuk mandiri serta ada kompetensi. Disamping itu kegiatan harus realistis dapat dilakukan oleh masyarakat.

b. Needs. Bidang yang dilakukan sesuai kebutuhan kelompok sasaran.

c. Packaging. Program yang dibuat dapat dikemas menarik agar mendapatkan sambutan positif dari masyarakat.

d. Branding. Ada upaya untuk membangun jejaring dengan tokoh masyarakat bisnis atau lainnya.

e. Profit. Harusnya produk yang digagas dapat menghasilkan benefit atau profit agar kegiatan dapat berkelanjutan.

f. System. SOP perlu dibuat sebagai aturan main dan untuk menghindari konflik.

g. Transparency. Dibuat audit dan laporan agar dapat dipercaya.

h. Persistency. Tidak mudah putus asa karena tantangan cukup besar dan rumit

Melalui UBSP ini masyarakat dapat meminjam dana dari UBSP dengan bunga yang ringan dan disepakati dan jika pada akhir tahun dilakukan tutup buku maka anggota masih mendapatkan pembagian hasil usaha seperti koperasi. Selama ini masyarakat telah mengenal dan melakukan kegiatan simpan pinjam, akan tetapi belum dikelola lebih produktif dan lebih fungsional untuk pengembangan wirausaha yang dijalani oleh kelompok maupun individu pribadi dari masyarakat tersebut. Melalui kegiatan ini tim akan melakukan kegiatan - kegiatan sebagai berikut :

1. Tim memberikan wawasan tentang UBSP manfaat dan mekanismenya. Tim membuat konsep awal atau dratft UBSP dan melakukan sosialisasi draft UBSP tersebut.

2. Tim membuat simulasi perhitungan keuntungan bagi anggota dan masyarakat (analisis Usaha)

3. Tim memberikan pengetahuan manajemen secara umum dan manajemen UBSP (6)

4. Tim memberikan pengetahuan manajemen keuangan UBSP (7)
5. Tim melakukan pendampingan dan membuat analisis usaha - usaha produktif yang dapat dilakukan (8)

6. Tim memberikan pelatihan pencatatan keuangan sederhana

7. Tim memberikan pelatihan mengelola keuangan usaha kecil (9)

Kegiatan - kegiatan tersebut merupakan alat untuk melakukan pemberdayaan dan pendampingan sebagai metode yang akan dilakukan dalam pengabdian masyarakat ini. Jadi metode yang disepakati dan akan dilakukan adalah pemberdayaan dengan pendampingan. Pemberdayaan adalah kegiatan tim memotivasi kelompok untuk mendorong semangatnya agar dapat membangun usaha berwirausaha untuk kemandirian (10). Tim melakukan diskusi, komunikasi dengan pengurus maupun kelompok secara efektif, meningkatkan kapasitas kelompok serta memberikan pelatihan. Setiap usaha atau bisnis dimulai dari gagasan yang dipelajari dengan tekun, dirancang dengan baik dan dilaksanakan. Proses perencanaan dapat memakan waktu yang lama dan penuh perjuangan melalui pendampingan dengan model bisnis canvas (11). Saat ini komunitas Aditya Yodha ini sedang mengawali proses dengan ide dukungan melalui UBSP AYO.

Kegiatan Pendampingan dilakukan secara virtula (online) maupun pertemnuan tatap muka

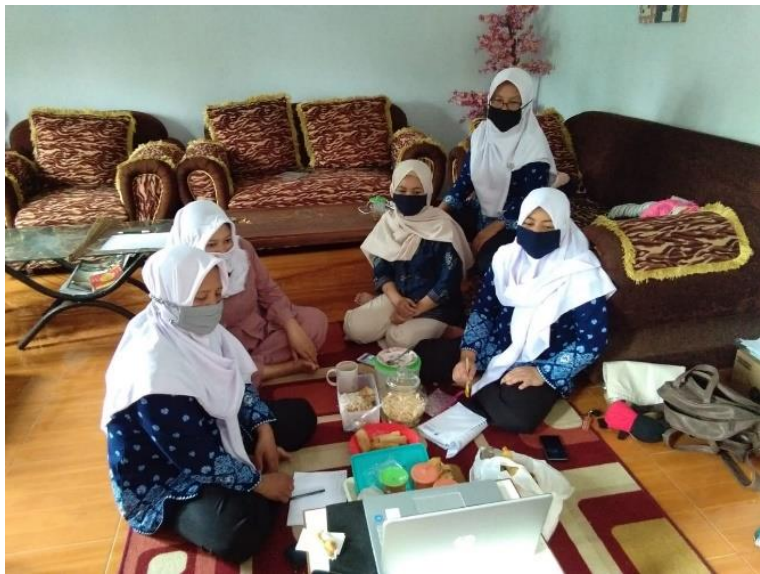

Kegiatan pelatihan

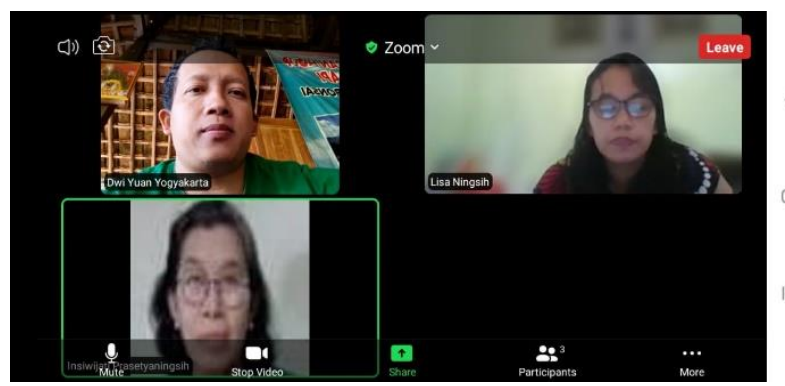

Kegiatan pendampingan 
Jadwal kegiatan pelatihan dan pendampingan sebagai berikut :

\begin{tabular}{|c|c|c|c|}
\hline No & Waktu & Kegiatan & Keterangan \\
\hline 1 & $\begin{array}{l}6 \text { April } \\
2021\end{array}$ & $\begin{array}{l}\text { Identifikasi } \\
\text { Permasalahan } \\
\text { di masa } \\
\text { pandemi }\end{array}$ & 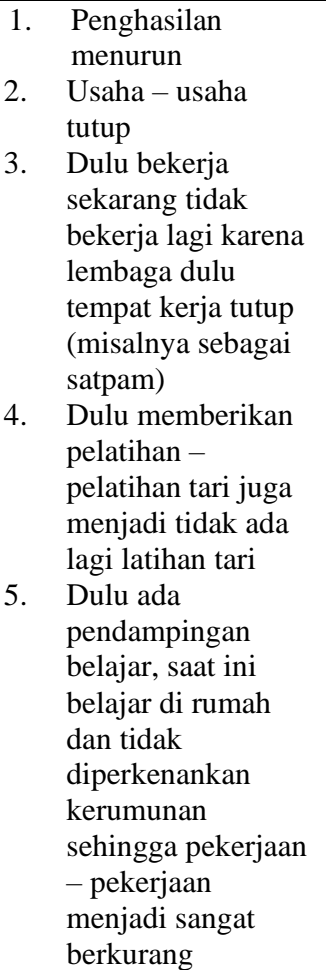 \\
\hline 2 & $\begin{array}{l}13 \\
\text { April } \\
2021\end{array}$ & $\begin{array}{l}\text { Identifkasi } \\
\text { pengembangan } \\
\text { usaha di masa } \\
\text { pandemi }\end{array}$ & $\begin{array}{l}\text { Ada beberapa } \\
\text { alternative usaha } \\
\text { potensial yang dapat } \\
\text { dikembangkan: } \\
\text { 1. Olahan salak } \\
\text { 2. Peternakan } \\
\quad \text { kambing } \\
\text { 3. Kolam ikan Nila } \\
\text { Untuk olahan salak, saat } \\
\text { ini mengalami kendala } \\
\text { bahan baku karena } \\
\text { panen salak tidak } \\
\text { melimpah dan harga } \\
\text { salak segar masih } \\
\text { normal, sehingga } \\
\text { masyarakat masih lebih } \\
\text { prioritas menjual salak } \\
\text { dalam bentuk buah } \\
\text { segar bukan bentuk } \\
\text { olahan salak. } \\
\text { Peternakan kambing, } \\
\text { baik kambing etawa } \\
\text { maupun kambing } \\
\text { domba masih tetap } \\
\text { prospektif dimasa } \\
\text { pandemi, karena } \\
\text { peternakan ini dapat } \\
\text { dilakukan di rumah } \\
\text { tangga masing - }\end{array}$ \\
\hline
\end{tabular}

\begin{tabular}{|c|c|c|c|}
\hline & & & $\begin{array}{l}\text { masing. Untuk susu } \\
\text { kambing otawa dapat } \\
\text { dijual di pabrik susu } \\
\text { yang bahan bakunya } \\
\text { dari susu kambing } \\
\text { otawa. } \\
\text { Untuk kambing domba, } \\
\text { dapat dijual kepada } \\
\text { penjual sate yang cukup } \\
\text { banyak di daerah } \\
\text { sleman, maupun daerah } \\
\text { istimewa Yogyakarta. }\end{array}$ \\
\hline 3 & $\begin{array}{l}20 \\
\text { April } \\
2021\end{array}$ & $\begin{array}{l}\text { Solusi Usaha } \\
\text { Kecil masa } \\
\text { pandemi }\end{array}$ & $\begin{array}{l}\text { Pemikiran awal yang } \\
\text { dikembangkan untuk } \\
\text { membantu usaha ternak } \\
\text { kambing adalah UBSP. } \\
\text { Diharapkan UBSP } \\
\text { dapat mendukung } \\
\text { rintisan usaha ternak } \\
\text { kambing dalam } \\
\text { keluarga, secara } \\
\text { bergantian. }\end{array}$ \\
\hline 4 & $\begin{array}{l}\text { Mei } \\
2021\end{array}$ & $\begin{array}{l}\text { Sosialisasi } \\
\text { draft UBSP }\end{array}$ & $\begin{array}{l}\text { 1. } \begin{array}{l}\text { Disampaikan } \\
\text { pengertian, }\end{array} \\
\text { manfaat, fungsi } \\
\text { dan tujuan } \\
\text { 2. } \\
\text { Pada awalnya } \\
\text { masyarakat merasa } \\
\text { kalau UBSP } \\
\text { berupa simpan } \\
\text { pinjam maka kuatir } \\
\text { jika menjadi racun, } \\
\text { hanya pinjam dan } \\
\text { tidak } \\
\text { mengembalikan }\end{array}$ \\
\hline 5 & $\begin{array}{l}4 \mathrm{Mei} \\
2021\end{array}$ & $\begin{array}{l}\text { Pemahaman } \\
\text { draft UBSP }\end{array}$ & $\begin{array}{l}\text { Membahas bagaimana } \\
\text { caranya agar UBSP } \\
\text { tidak menjadi pinjaman } \\
\text { macet tetapi pinjaman } \\
\text { produktif membantu } \\
\text { masyarakat }\end{array}$ \\
\hline 6 & $\begin{array}{l}\text { 4 Mei } \\
2021\end{array}$ & $\begin{array}{l}\text { Pemahaman } \\
\text { draft UBSP }\end{array}$ & $\begin{array}{l}\text { Melalui UBSP dibuat } \\
\text { aturan ketentuan. } \\
\text { Sebelum membuat } \\
\text { ketentuan atau aturan } \\
\text { maka dibentuk } \\
\text { kepengurusan UBSP. } \\
\text { Selanjutnya dibentuk } \\
\text { kelembagaan UBSP } \\
\text { dengan nana AYO } \\
\text { (singkatan dari Aditya } \\
\text { Yodha). Pengurus } \\
\text { UBSP seperti terlampir }\end{array}$ \\
\hline 7 & $\begin{array}{l}11 \mathrm{Mei} \\
2021\end{array}$ & $\begin{array}{l}\text { Pemahaman } \\
\text { UBSP }\end{array}$ & $\begin{array}{ll}\text { 1. } & \text { Membuat Profil } \\
\text { UBSP } \\
\text { 2. } \\
\text { Memikirkan aturan } \\
\text { - aturan dalam } \\
\text { UBSP (sedang } \\
\text { dalam proses }\end{array}$ \\
\hline
\end{tabular}




\begin{tabular}{|c|c|c|c|}
\hline & & & $\begin{array}{l}\text { membuat aturan } \\
\text { yang sederhana } \\
\text { dan mudah } \\
\text { dipahami) }\end{array}$ \\
\hline 8 & $\begin{array}{l}25 \mathrm{Mei} \\
2021\end{array}$ & $\begin{array}{l}\text { Pemahaman } \\
\text { tentang } \\
\text { Manajemen } \\
\text { dan Organisasi }\end{array}$ & $\begin{array}{ll}\text { 1. } & \text { Berdasarkan } \\
\text { pembentukan } \\
\text { pengurus UBSP } \\
\text { maka dibuat } \\
\text { struktur organisasi } \\
\text { untuk membuat } \\
\text { pembagian tugas } \\
\text { bagi pengurus dan } \\
\text { anggota } \\
\text { 2. } \\
\text { Mempelajari } \\
\text { manajemen yang } \\
\text { terdiri dari } \\
\text { perencanaan, } \\
\text { pelaksanaan, } \\
\text { monitoring dan } \\
\text { evaluasi serta } \\
\text { tindak lanjut }\end{array}$ \\
\hline 9 & 8 Juni & Sda & $\begin{array}{l}\text { Pemahaman tentang } \\
\text { perencanaan, belajar } \\
\text { membuat perencanaan } \\
\text { UBSP: } \\
\text { 1. Rencana dana yang } \\
\text { dimiliki } \\
\text { 2. Rencana } \\
\text { menggulirkan dana } \\
\text { untuk pembelian } \\
\text { kambing } \\
\text { 3. Rencana } \\
\text { memberikan } \\
\text { kontribusi untuk } \\
\text { kegiatan sosial } \\
\text { komunitas }\end{array}$ \\
\hline 10 & 8 Juni & Sda & $\begin{array}{l}\text { Mempelajari } \\
\text { prakteknya }\end{array}$ \\
\hline 11 & & Sda & $\begin{array}{l}\text { Masih melanjutkan } \\
\text { belajar membuat } \\
\text { perencanaan UBSP, } \\
\text { menentukan iuran } \\
\text { Wajib, iuran pokok } \\
\text { dengan hasil seperti } \\
\text { terlampir. }\end{array}$ \\
\hline 12 & $\begin{array}{l}8 \text { Juni } \\
2021\end{array}$ & Sda & $\begin{array}{l}\text { Membahas bagaimana } \\
\text { melaksanakan rencana: } \\
\text { 1. } \\
\text { Pelaksanaan ini } \\
\text { merupakan sarana } \\
\text { belajar untuk } \\
\text { menjadi pemimpin } \\
\text { (coordinator bagi } \\
\text { pengurus UBSP } \\
\text { dan anggotanya) } \\
\text { 2. Ada pertemuan } \\
\text { koordinasi yang } \\
\text { rutin, untuk } \\
\text { membahas } \\
\text { perkembangan } \\
\text { pelaksanaan UBSP }\end{array}$ \\
\hline
\end{tabular}

\begin{tabular}{|c|c|c|c|}
\hline & & & $\begin{array}{l}\text { 3. Ada evaluasi dan } \\
\text { monitoring dari } \\
\text { dana yang } \\
\text { dipinjam dan } \\
\text { melihat } \\
\text { perkembangan } \\
\text { usaha peternakan } \\
\text { kambingnya. } \\
\end{array}$ \\
\hline 13 & $\begin{array}{l}15 \text { Juni } \\
2021\end{array}$ & $\begin{array}{l}\text { Memahami } \\
\text { manajemen } \\
\text { Keuangan } \\
\text { sederhana } \\
\text { untuk UBSP } \\
\end{array}$ & $\begin{array}{l}\text { Seluruh anggota belajar } \\
\text { manajemen keuangan } \\
\text { sederhana untuk UBSP }\end{array}$ \\
\hline 14 & $\begin{array}{l}15 \text { Juni } \\
2021\end{array}$ & Sda & $\begin{array}{l}\text { Masih proses belajar } \\
\text { bersama }\end{array}$ \\
\hline 15 & $\begin{array}{l}\text { 22 Juni } \\
2021\end{array}$ & $\begin{array}{l}\text { Memahami } \\
\text { cara } \\
\text { pencatatan } \\
\text { keuangan } \\
\text { UBSP }\end{array}$ & $\begin{array}{l}\text { Seluruh anggota belajar } \\
\text { tentang pencatatan } \\
\text { keuangan }\end{array}$ \\
\hline 16 & $\begin{array}{l}\text { 22 Juni } \\
2021\end{array}$ & $\begin{array}{l}\text { Memahami } \\
\text { analisis usaha }\end{array}$ & $\begin{array}{l}\text { Seluruh anggota belajar } \\
\text { analisis usaha }\end{array}$ \\
\hline 17 & $\begin{array}{l}\text { 29 Juni } \\
2021\end{array}$ & $\begin{array}{l}\text { Penyaluran } \\
\text { dana kambing }\end{array}$ & $\begin{array}{l}\text { Telah dibeli kambing } \\
\text { etawa untuk Bp Saidi } \\
\text { seharga Rp } 3.100 .000\end{array}$ \\
\hline 18 & $\begin{array}{l}29 \text { Juni } \\
2021\end{array}$ & $\begin{array}{l}\text { Membahas } \\
\text { mekanisme } \\
\text { pengembalian } \\
\text { pinjaman }\end{array}$ & $\begin{array}{l}\text { Saat ini pembagian } \\
\text { masih 30\%: } 70 \% \text {, akan } \\
\text { tetapi akan melakukan } \\
\text { pembahasn lanjut } \\
\text { pengembalian dan } \\
\text { bung, apakh itu yang } \\
\text { 30\% setiap penjualan } \\
\text { atau hasil sehingga } \\
\text { dapat tertutp pinjmana } \\
\text { nya.dan pembahasan } \\
\text { alternative lain, draft } \\
\text { kemungkinan yang } \\
\text { dapat dilakukan }\end{array}$ \\
\hline 19 & $\begin{array}{l}6 \text { Juli } \\
2021\end{array}$ & $\begin{array}{l}\text { Membentuk } \\
\text { pengurus } \\
\text { UBSP }\end{array}$ & $\begin{array}{l}\text { Ketua : Marwanto } \\
\text { Sekretaris : nanik } \\
\text { Bendahara : Ani }\end{array}$ \\
\hline 20 & & $\begin{array}{l}\text { Tindak lanjut } \\
\text { UBSP }\end{array}$ & $\begin{array}{l}\text { Mengembangkan } \\
\text { pendanaan UBSP } \\
\text { dengan cara melakukan } \\
\text { jejaring atau } \\
\text { memanfaatkan } \\
\text { Musrenbangdes }\end{array}$ \\
\hline 20 & & $\begin{array}{l}\text { Pemanfaatan } \\
\text { UBSP }\end{array}$ & $\begin{array}{ll}\text { 1. } & \text { Dana kambing } \\
& \text { Etawa (Pak Edi) } \\
\text { 2. } & \text { Dana kambing } \\
\text { domba (Pak } \\
\text { Haryanto) }\end{array}$ \\
\hline
\end{tabular}

Kegiatan - kegiatan usaha yang selama ini telah dilakukan dan akan dikembangkan melalui UBSP adalah:

a. Usaha pemeliharaan kambing Etawa 


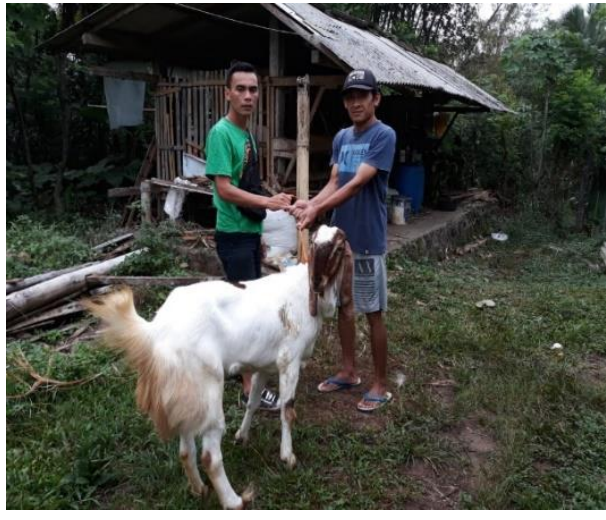

b. Usaha pemeliharaan kambing Domba

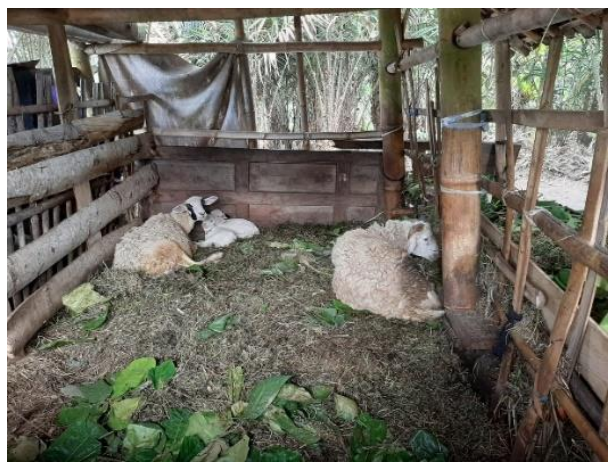

c. Usaha pemeliharaan Ikan Nila

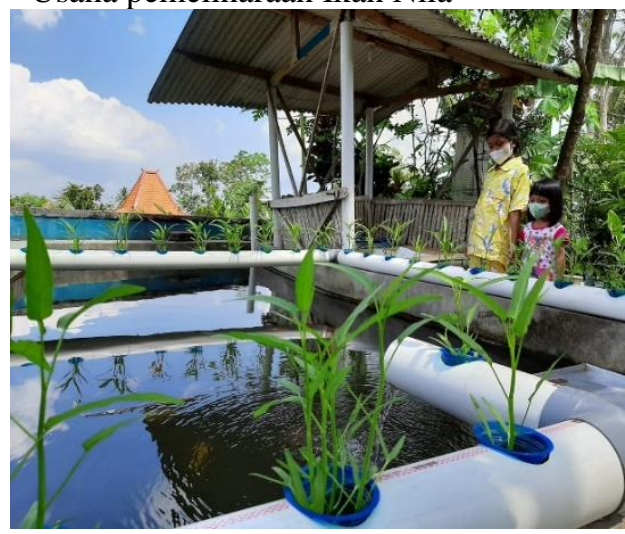

Berdasarkan kegiatan - kegiatan yang telah dilakukan maka diharapkan UBSP dapat berjalan dan dapat membantu kelompok untuk mengembangkan usaha. Melalui UBSP peternakan kambing domba atau kambing etawa, ikan Nila dapat berkembang secara perlahan tetapi pasti, dengan dukungan dana yang sudah ada di kelompok dan dana dari musrenbangdes yang terakumulasi. Melalui peternakan kambing dan budidaya Ikan Nila dan UBSP AYO masyarakat semakin sejahtera dan dapat mengurangi atau menghapus permasalahan kemiskinan atau kebutuhan hidup dimasa pandemi sehingga kendala atau permasalahan keluarga dapat ditanggulangi. Peternakan juga merupakan suatu upaya ketahanan keluarga melalui ketahanan pangan melalui usaha peternakan. Dalam masa pandemic ada kendala pertemuan - pertemuan yang harus dilakukan. UBSP yang dikembangkan juga merupakan UBSP dengan prinsip kas kosong, yaitu uang selalu digulirkan atau disimpan di bank.

Dari seluruh proses pengabdian kepada masyarakat yang dilakukan secara perlahan dapat mengubah pola pikir dan cara pandang masyarakat untuk mampu mengembangkan potensi lingkungan sekitar, agar lebih berdaya. Melalui pembentukan UBSP ini diharapkan dapat mendukung kreativitas gagasan masyarakat sehingga berdaya, tangguh, masyarakat lebih sejahtera dan mandiri.

\section{UCAPAN TERIMA KASIH}

Kami mengucapkan terima kasih atas kesempatan dan dukungan dari fakultas dalam melakukan pengabdian masyarakat di Dusun Sorowangsan Turi. Harapannya kegiatan pengabdian masyarakat ini dapat memberikan harapan dan mengurangi kemiskinan di seluruh wilayah pelaksanaan pengabdian masyarakat.

\section{DAFTAR PUSTAKA}

[1] I. Prasetyaningsih, PkM Penguatan Manajemen \& Pengurusan Ijin Usaha Kelompok Salak Olahan Sorowangsan Girikerto, Turi, Sleman, Peran Peerguruan Tinggi dalam Transformasi, Adaptasi, dan Metamorfosisi Pengabdian pada Masyarakat di Era New Normal, hal 253 - 256, 17 September 2020

[2] https://field-indonesia.or.id/usaha-bersama-simpan-pinjam/

[3] YA Prihatno, A Halim. Z Zulkifli, Analisis Strategi UMKM Berbasis Sumberdaya Lokal dengan Pendekatan Pemberdayaan masyarakat Kecamatan Pituruh, 2019. Eprint.stieww.ac.id

[4] A. Maskur, Resep Bisnis Ciputra, Mengubah kotoran dan rongsokan menjadi emas, 2018 https://www.google.co.id/search?tbm=bks\&hl=id\&q=quantum+leap+t erbaru+ciputra

[5] Sudarmadi, Tak Cukup Bermodal Niat Baik, Swa 21/XXXI/31 September - 13 Oktober 2015. Jakarta, Penerbit : PT Swasembada Media Bisnis. Jakarta

[6] T. Ibrahim, H.A. Rusdiana, Manajemen Mutu Terpadu, Bandung, penerbit Yrama Widya, April 2021

[7] V. Horne, prinsip - prinsip Manajemen Keuangan, Jakarta Penerbit salemba empat, 2017.

[8] S. Hrahap, Studi Kelayakan Bisnis : Pendekatan Integratif, cetakan pertama, Febi Uin SU Pres 2018

[9] S. Maryanti, Manajemen Usaha kecil, Penerbit Deepublish 2017

[10] H. P. Dewi, Entrepreneur Talks : Tujuh Stretegi Mengembangkan Bisnis, Jogjakarta, Penerbit Stiletto Book 2018.

[11] T. Tim PPM Manajemen, Business Model Canvas, Jakarta, Penerbit PPM Manajemen Jakarta, 2013 